\title{
Proposal for a Process oriented Knowledge Management System (PKMS)
}

\author{
Ludovic LOUIS-SIDNEY ${ }^{1}$, Vincent CHEUTET ${ }^{2}$, Samir LAMOURI ${ }^{3}$ \\ ${ }^{1}$ Laboratoire Quartz EA7393, SUPMECA, 3 rue Fernand Hainaut, 93400 Saint-Ouen, France - \\ ludovic.louissidney@gmail.com
}

Mr. Ludovic Louis-Sidney was graduated in 2008 at SUPMECA Paris, in production engineering speciality. He obtained his PhD thesis in 2011 from Ecole Centrale Paris in industrial engineering. His $\mathrm{PhD}$ research work was performed in collaboration with Renault Powertrain Technology Department.

${ }^{2}$ Université de Lyon, INSA Lyon, DISP EA4570, Bât Léonard de Vinci, 21 avenue Jean Capelle, 69621 Villeurbanne cedex, France - vincent.cheutet@insa-lyon.fr

Pr. V. Cheutet obtained in 2006 a PhD degree in the field of Mechanical engineering from both the Grenoble-INP engineering school (France) and the University of Genoa (Italy). From 2007 to 2014, he worked at SUPMECA Paris (engineering school) as associate professor. He became full professor in 2014 at INSA Lyon, in first cycle department. He joined the DISP Laboratory and is currently leader of the "Information Systems Agility" team. Pr. V. Cheutet has published more than 50 papers in international journals and conferences. His main research topics are industrial information systems (especially PLM and ERP), knowledge management, industrial and mechanical engineering management.

${ }^{3}$ UMR 8201 CNRS (LAMIH) Laboratoire d'automatique et de mécaniques industrielles et humaines, Arts et Métiers Paritech, 151 boulevard de l'Hôpital, 75013 Paris, France - samir.lamouri@ensam.eu

Pr. S. Lamouri is a Professor of Mechanical Engineering and Information Technology in the Department of Mechanical Engineering at Arts et Métiers ParisTech, France. He has been involved in several research projects about supply chain management and information systems. His research interests deal with supply chain management, information sharing and exchange, PLM, APS, ERP systems, collaborative practices, and their impacts on enterprise performance. 


\begin{abstract}
:
In an increasingly competitive environment, manufacturing companies are more frequently looking to handle the knowledge referentials relating to their redesign processes. They are then able to implement this with less effort and balance out their work capacity for innovation activities, contributing to more significant improvements in their product offering. In this article we propose a conceptual model for the implementation of a process-oriented knowledge tool dedicated to the formalization of this type of knowledge referential. The implementable nature of this model has been validated by a demonstrator tested on an application case provided by our industrial partner, Renault Powertrain Technology Department.
\end{abstract}

Keywords: Knowledge, Redesign process, Conceptual model, Information system

\title{
1 Introduction
}

If innovation is recognized as a market driver, $80 \%$ of design process activities are routine activities in the manufacturing sector (Stokes, 2001), (Bluntzer et al., 2009). The processes composed of these activities, which (Gero, 1990) qualifies as redesign processes, are mainly based on reuse of the knowledge generated by individuals from previous design processes. The ability to memorise this knowledge in order to speed up integration by individuals constitutes an opportunity to optimise the cost of product redesign processes by reducing lead times.

As a consequence, manufacturing companies have shown a growing interest in Knowledge Management, considering it a real competitive advantage (Anantatmula, 2010). Knowledge management systems are so born to provide the required knowledge at the right time, to the right agent, in the required form (Bernard and Tichkiewitch, 2008). Specific tools are therefore required in order to maintain control over this asset in the context of product design, namely, Knowledge Management Tools (KMT).

The authors of (Vaccaro et al., 2010) point out that these KMTs can affect financial performances by improving inter-firm relationships in two ways: guaranteeing more efficient knowledge-based processes and cost reduction and improving innovation-related drivers of profits (e.g. product and service performance). It is worth mentioning that the outcomes of KMTs on organizational processes are directly related to how these tools are used (Alavi and Leidner, 2001). Indeed, while the literature has unanimously acknowledged the positive potential impact of KMTs on organizational activities, some empirical studies have pointed out that organizations can face several difficulties in effectively exploiting these tools (D'Adderio, 2003), (Henderson, 1991). Moreover, studies carried out by (Ahmed and Wallace, 2004) found that designers are not always aware of their knowledge needs and in particular supporting novice designers by simply supplying knowledge may not be enough; they also need to be aware of what they need to know.

To achieve an efficient knowledge-based design environment, the following areas of research in knowledge-based systems were envisioned in (Szykman et al., 2001):

- Development of a comprehensive representation for product development knowledge,

- Integration of traditional engineering software with knowledge-based applications,

- Mechanisms for indexing, searching, and retrieving design cases,

- Design rationale capture and conflict mitigation,

- Need for commercial CAD/CAM/CAE vendors to support knowledge design, knowledge capture and reuse.

Although much progress has been made since this paper, (Chandrasegaran et al., 2013) demonstrate that there is not a widespread use of knowledge-aided systems in the industry. In particular, in our industrial partner, if knowledge enrichment has a current high-level maturity, 
knowledge diffusion and sharing have a strong potential for improvement. Thus, we identify the following research gap: there are needs for visibility over the relationship that exists between a knowledge support tool and a redesign process, i.e. knowing the best knowledge to use at the best time.

In this paper, we propose a conceptual model that targets the implementation of a knowledge management tool: PKMS (Process oriented Knowledge Management System). This tool will help support and offer visibility over their studies relative to the operationalisation of knowledge in product redesign processes in light of the various tools that can be implemented. It has two characteristics:

- The use of formalism tailored to the human memory to access the information source of the knowledge imparted,

- The introduction of the process concept, enabling the interaction that exists between a redesign process and knowledge support tools to be formally expressed.

The paper is structured as follows. Section 2 reviews the main issues in knowledge management to justify our choice of process-oriented knowledge valorisation strategy. Section 3 develops the conceptual model of PKMS. Section 4 details the implementation choices of the tool and the main results of the deployment of the PKMs tool in our industrial partner. Section 5 offers conclusions and research perspectives raised by our proposition.

\section{State of the art on Knowledge Management}

\subsection{Knowledge characterization}

If knowledge has different definitions according to context (see (Chandrasegaran et al., 2013) for an exhaustive review of such definitions), in this paper we choose the point of view of Tsuchiya, who introduces a distinction between datum, information and knowledge: "Although terms "datum", "information" and "knowledge" are often used interchangeably, there exists a clear distinction among them. When datum is sense-given through interpretative framework, it becomes information, and when information is sense-read through interpretative framework, it becomes knowledge" (Tsuchiya, 1993). Furthermore, knowledge is stable (Zins, 2007), which means it has a repeatable implementation.

The knowledge-creation process described here was analysed by (Grundstein, 2012) and led the author to establish the postulate that "Knowledge exists in the interaction between an Interpretative Framework (incorporated within the head of an individual, or embedded into an artefact), and data". In contrast, data can be seen as a perceptible sign that is separate from any interpretative framework and information, as data is put through an interpretative framework, the link to which has been broken. A point of view therefore results from this former aspect, whereby the subject that has transmitted the information may perceive it as knowledge, whereas the one receiving it only perceives it as data and will give it a potentially different meaning from the subject that has transmitted it. This is therefore referred to as the "information source for knowledge" (Grundstein, 2012).

Knowledge can be classified according to several dimensions (Baumard, 1999), (Chandrasegaran et al., 2013):

- Formal Vs. Tacit,

- Individual Vs. Collective,

- Product Vs. Process,

- Compiled Vs. Dynamic.

In particular, (Chandrasegaran et al., 2013) propose a classification of knowledge representation according to the design phases (Figure 1). The design stages shown at the top are based on (Pahl et al., 2007). The columns below each stage of design show examples of representations of knowledge used at each stage. These are then tagged as (P)ictorial, (S)ymbolic, 
(L)inguistic, (V)irtual and (A)lgorithmic, using a knowledge representation classification proposed by (Owen and Horvath, 2002).

The formal expression of knowledge therefore resides in a representation of the whole - data, semantics and contextualisation - that is as faithful as possible. To convey this representation, a support medium is required. Knowledge objects are one such medium (Baizet, 2004), (Cacciatori, 2008).

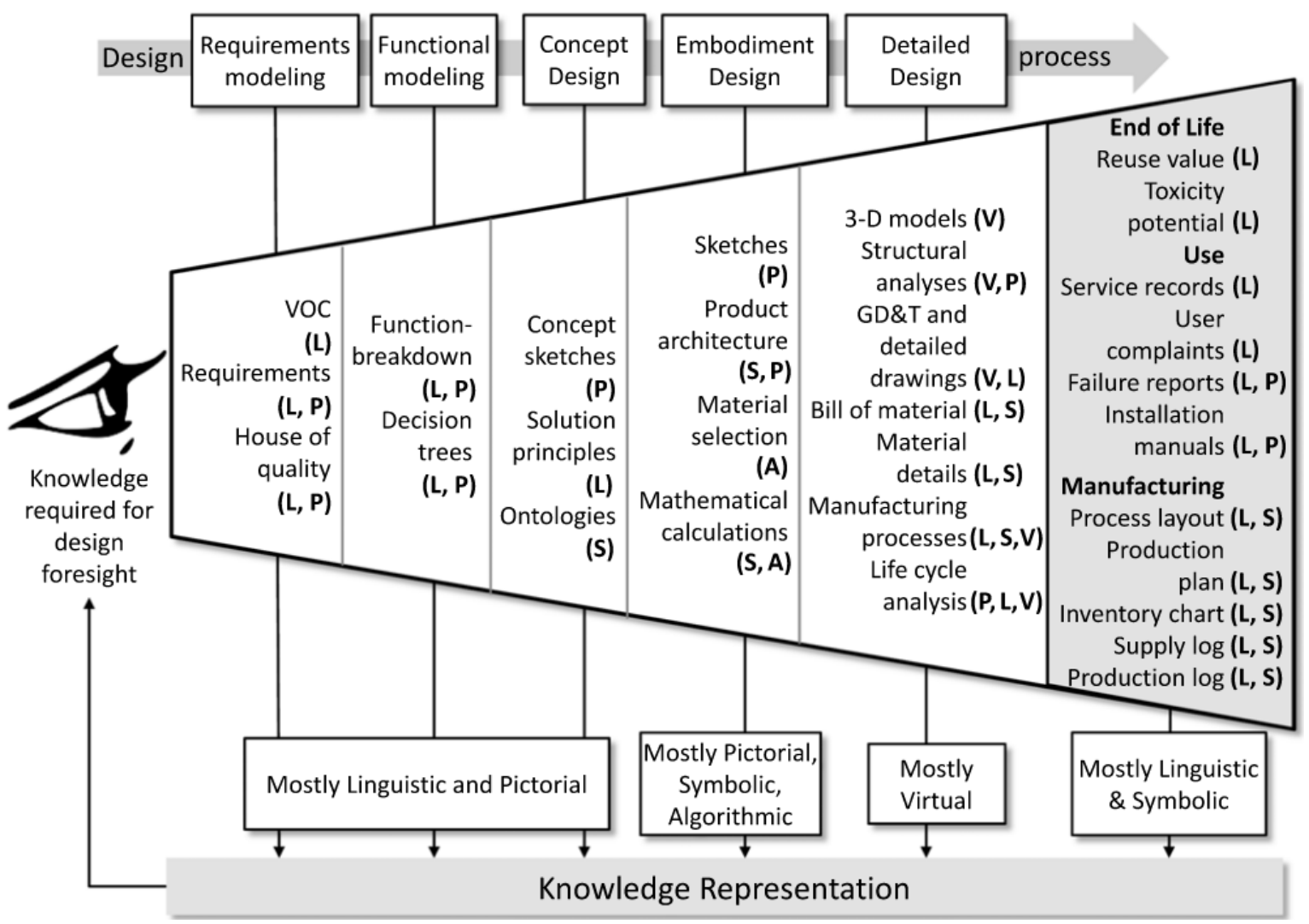

Figure 1: Knowledge representations in product design (Chandrasegaran et al., 2013).

\subsection{Knowledge valorisation strategies in companies}

To satisfy the issues at stake in the valorisation of knowledge, there are two main strategies of approach: approaches that focus on the reification of knowledge and those that focus on individuals as holders of knowledge ( $\mathrm{Ng}$ et al., 2012). (McMahon et al., 2004) summarises the various terms relative to these approaches as: "commodity view", "codification" and "object view" for the first and "community view", "personalisation" and "process view" for the second.

Personalisation approaches cover the various knowledge transformation mechanisms as applied within an individual or between individuals (Figure 2) when they are freely expressed and lead to solutions oriented towards practice communities (Beylier et al., 2009), (Vroom and Olieman, 2011) as well as CSCW-type (Computer-Supported Collaborative Work) tools (Karacapilidis, 2002).

Codification approaches cover the elicitation of knowledge in a controllable form beyond the actual individual and are, for the most part, based on information and communication technology (Chen and Huang, 2012). This explicit knowledge desynchronised from the interpretative framework of individuals then takes on a dual information/knowledge status. The simple documents, codified in line with the interpretative framework of the individuals who will read them, will be a source of knowledge for them similar to that of the people who wrote these documents. In this case, it becomes possible to consider these documents as knowledge. Otherwise, they will be the information source of knowledge. 
Moreover, the information embedded in expert systems constitutes the intrinsic knowledge of these systems inasmuch as they are able to use it to reason via their own interpretative patterns.

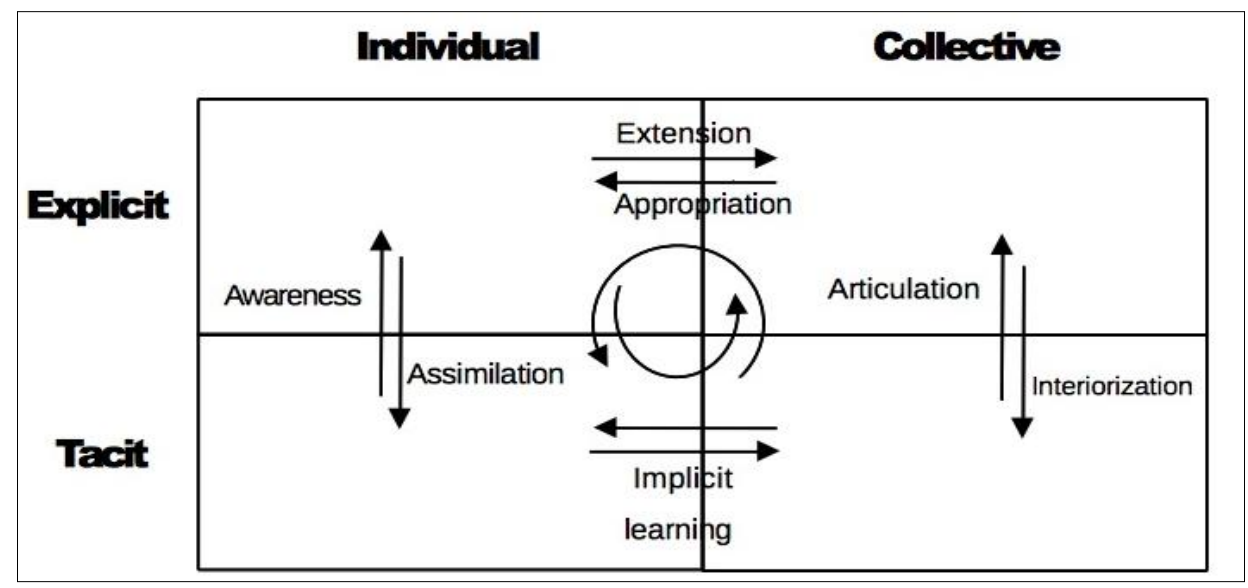

Figure 2: Mechanisms for the transformation of knowledge between and within individuals (Baumard, 1999).

While the two approaches tackle knowledge in a different manner, they are complementary as far as companies are concerned. It should be noted that personalisation approaches, due to human meta-reasoning ability, are particularly agile in relation to the knowledge life-cycle of human beings (Figure 2). However, codification offers the advantage of involving fewer human resources and/or gaining in terms of product redesign process lead times. Nonetheless, it introduces information/knowledge ambiguity that needs to be minimised. The complementarity of these two approaches leads us to believe that it might be better to consider knowledge as a resource distributed within a network of players and IT technology as initially proposed by Siemens and Downes via the connectivism concept (Kop and Hill, 2008) and take action at the level of their interface.

\subsection{Knowledge support tools in design}

KMTs were defined by (Ruggles, 1997) as technologies for knowledge generation, codification and transfer. The context of KM implementation is often complex and highly dynamic, and various types of tools have been developed for various applications (Tiwana and Ramesh, 2001).

In his analysis of the literature produced between 1995 and 2002 on the technology and applications covered by knowledge management, (Liao, 2003) identified seven technical areas, which we propose combining as follows:

- Framework (1) and modelling (2),

- artificial intelligence (KBS (3) and expert systems (4)),

- databases (5), data mining (6) and information and communication technology (ICT) (7) (e.g. the Internet, Extranets and wireless web, etc.).

The technical fields that cover the tools made directly available to product designers to carry out their redesign activities, supporting the codified knowledge, are those of artificial intelligence for a very formal approach, and databases, data mining and ICT where less formal codification approaches are used. Figure 3 proposes an overview of existing knowledge methods and tools according to the type of knowledge strategy. 


\begin{tabular}{|c|c|c|c|c|c|c|}
\hline \multirow[b]{2}{*}{ METHODS } & \multicolumn{2}{|c|}{$\begin{array}{l}\text { KNOWLEDGE } \\
\text { MANAGEMENT }\end{array}$} & & \multicolumn{3}{|c|}{ KNOWLEDGE ENGINEERING } \\
\hline & $\begin{array}{c}\text { GAMETH } \\
\text { [Grundstein et } \\
\text { Rosenthal-Sabroux, } \\
\text { 2004] }\end{array}$ & $\begin{array}{l}\text { MEREX } \\
\text { [Corbel, 1997] }\end{array}$ & $\begin{array}{c}\text { MASK } \\
\text { [Ermine, 2001] }\end{array}$ & $\begin{array}{c}\text { CommonKADS } \\
\text { [KADS, 2011] }\end{array}$ & $\begin{array}{l}\text { MOKA } \\
\text { [MOKA, 2000] }\end{array}$ & $\begin{array}{c}\text { CBR } \\
\text { [Watson, 1999 }\end{array}$ \\
\hline $\begin{array}{l}\text { KNOWLEDGE } \\
\text { BASED TOOLS }\end{array}$ & \multicolumn{2}{|c|}{ Knowledge objects } & $\begin{array}{c}\text { Knowledge } \\
\text { book }\end{array}$ & $\begin{array}{c}\text { Knowledge } \\
\text { Based } \\
\text { System }\end{array}$ & $\begin{array}{l}\text { Knowledge } \\
\text { Based } \\
\text { Engineering } \\
\text { Application }\end{array}$ & $\begin{array}{c}\text { CBR } \\
\text { System }\end{array}$ \\
\hline
\end{tabular}

Figure 3: Overview of KM methods and tools according to KM strategy.

Knowledge engineering covers methods of a formal nature "derived from artificial intelligence and cognitive science" (Zacklad and Grundstein, 2001). CommonKADS (Kingston, 1998) and MOKA (MOKA, 2000) are therefore examples of methods obtained from ESPRIT European programmes known to manufacturers that enable KBE (Knowledge Based Engineering) applications to be developed (Verhagen et al., 2012). The CBR (Cased-Based Reasoning) (Watson, 1999) method focuses on KBS (Knowledge Based Systems) that enable a solution to be provided for a problem, based on the comparison of previous solutions proposed to deal with similar problems. The expert systems developed are based on technology similar to that of artificial intelligence and are designed to perform repetitive tasks calling for a complex, rigorous work approach. They continue to be developed in the world of industry using a language such as OWL (W3C, 2012), for example, for the modelling and interpretation of rules (Fortineau et al., 2014).

Other tools are of an informal kind, inasmuch as the knowledge codification method used is based on simple formalism highlighting the aspects of review and accessibility to as many people as possible. These types of support constitute static knowledge objects (identical irrespective of the product being developed) or reconfigurable ones (that can be adapted to the product during development) and are widely used in companies despite the fact that they are redundant and, in certain cases, result in a need to supervise their use (Louis-Sidney et al, 2011). Once the number of knowledge objects becomes high, the valorisation of the knowledge codified on informal supports, as described above, is dependent upon the attendant management solution - "Knowledge may not be able to be effectively retrieved from these memory banks depending on such factors as the storage capacity of these repositories, their persistence and reliability over time, the quality of their indexing" (Cacciatori, 2008). The databases and additional research solutions (data mining) then become the daily tools of designers in their activity (Triantaphyllou et al., 2002). These databases may vary considerably according to the type of ICT selected: an Intranet, groupware, content management system, document management systems, relational and object databases, workflow systems (Ngai and Chan, 2005; Vaccaro et al., 2010). Several of these solutions are often present in companies and lead to diversification of the location of the knowledge objects, as well as to actual difficulties for designers in finding them or determining whether they exist.

\subsection{Interaction between knowledge support tools and redesign processes}

The valorisation of a company's knowledge notably occurs within product redesign processes and represents an opportunity to reduce the related lead time and cost. Understanding the relationship between a knowledge object, its support tool and a redesign process is therefore essential and must be contributed by the unified structuring model for knowledge support tools. 
Finally, in the automotive industry, several approaches have been developed to link knowledge objects with the particular design strategy employed in such an industry. One is the Project Knowledge Management strategy, defined as "knowledge management in project situations and thus the link between the principles of knowledge management and project management" (Hanisch et al., 2009), which has been deployed with success in the automotive industry (Johansson et al., 2013). Nevertheless, such a strategy is known to be totally dependent on the organisation and cannot be easily generalised.

As a consequence, a vision of knowledge management that links a knowledge object to a process view of the design easily fits into the managerial policy of a company that has chosen a process-drive method of management as recommended by the International Organisation for Standardisation, and seems to be well accepted by manufacturing companies. It assumes that "for organizations to function effectively, they have to identify and manage numerous interrelated and interacting processes" (ISO 9000, 2005) and invites companies to formally express them. The processes concerned are to be identified from an approach oriented towards external and internal customers, corresponding to a "set of interrelated or interacting activities, which transforms inputs into outputs". This is why we choose such a strategy in our proposition.

\section{Conceptual model}

In this section, we propose a conceptual model; that is to say, a model that enables its authors to bridge the gap between the mental representation of the solution they propose and the solution itself (Ben-Ari and Yeshno, 2006). It describes a solution from a designer's standpoint and constitutes a Computational Independent Model (CIM)-type of conceptual model following a Model Driven Architecture (MDA) approach (Miller and Mukerji, 2003).

\subsection{Methodological support}

The model proposed is based on the framework of the MASK method, details of which are not given in full in this paper. The reader should see (Ermine, 2005) for a more precise description. This framework proposes codifying the knowledge based on the combination of a systemic approach with a semiotic approach. The systemic approach combines the ontological, phenomenological and evolutionary components of a system. The semiotic approach combines the syntaxical, semantic and contextual components of the knowledge. We paid particular attention to the semantic, contextual, ontological, phenomenological and evolutionary components, along with some of their combinations, in order to achieve the three objectives set out above. The semantic component refers to the meaning of the sign and calls upon linguistics, semiotics and anthropology. In particular, its aim is to make it possible to codify knowledge according to principles that enable the meaning to be extracted from it and therefore limit information/knowledge ambiguity. The contextual component comes from within the field of psychosociology and its aim is to place the knowledge within its context. The ontological component proposes a description of the knowledge perceived to be static. The phenomenological component proposes a dynamic descriptive view of the use of knowledge. The evolutionary component covers the dynamics of the knowledge itself or its life-cycle.

\subsection{Model architecture}

The architecture of the proposed conceptual model is shown in Figure 4.

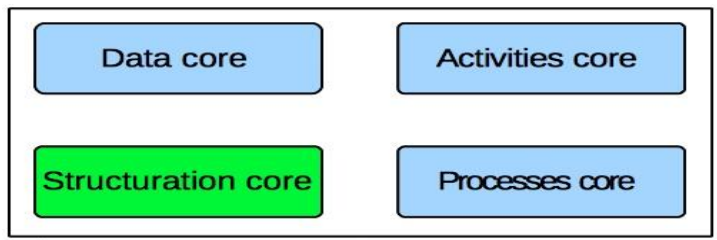


Figure 4: Conceptual model architecture.

The knowledge support tools identified in Section 2 are either static or reconfigurable knowledge objects or expert systems to assist or even replace human beings in their activities in a metier redesign process. This analysis leads to the determination of three key elements: the datum, the activity and the process.

The aim of the datum element is to represent any static type of knowledge source. The activity and process elements mark operationalisation of the knowledge or its use. They notably represent the expert systems. Nonetheless, as these elements are more generic than that of the expert system, they enable those redesign activities and processes supported by them and those redesign activities and processes not supported by them to be highlighted. Moreover, to avoid any ambiguity, the activity and process elements have been considered separately, an activity being an atomic data transformation stage in the breakdown of a process. In the remainder of this paper, we will call these three elements Codified Explicit Knowledge Quantums (CEKQs). A CEKQ is defined as being the tiniest measurement of codified explicit knowledge considered to be a point of interest for which it is possible to envisage a more complete description. It is characterised by a finite number of data (or perceptible manifestations). Within the numerical space considered by our work, it is expressed by a finite number of words, figures or images.

The structuring core encapsulates the network models that enable specific CEKQs to be obtained via faceted classification. Over and above this aspect, its browsable nature also means that the position of a CEKQ can be quickly assessed in relation to the organisation's field of knowledge. The structuring core is unique and thus constitutes the entry point of the conceptual model. The Data, Activities and Processes cores each encapsulate types of CEKQs targeted by the model. They reflect the formalism of the properties' models.

\subsection{CEKQs models}

The Datum class (Figure 5) encapsulates the name of a static or reconfigurable knowledge object associated with a description enabling its subject to be summarised and the person in charge. An identifier (id) provides the possibility of uniquely finding a knowledge object, some of which may have identical names according to the departments of the organisation in question. The RelationDD class represents the link that exists between two knowledge objects when one refers to the other and vice versa when one is used as a reference by the other. This link is of the same type as the one expressed in the "references" section of scientific articles.

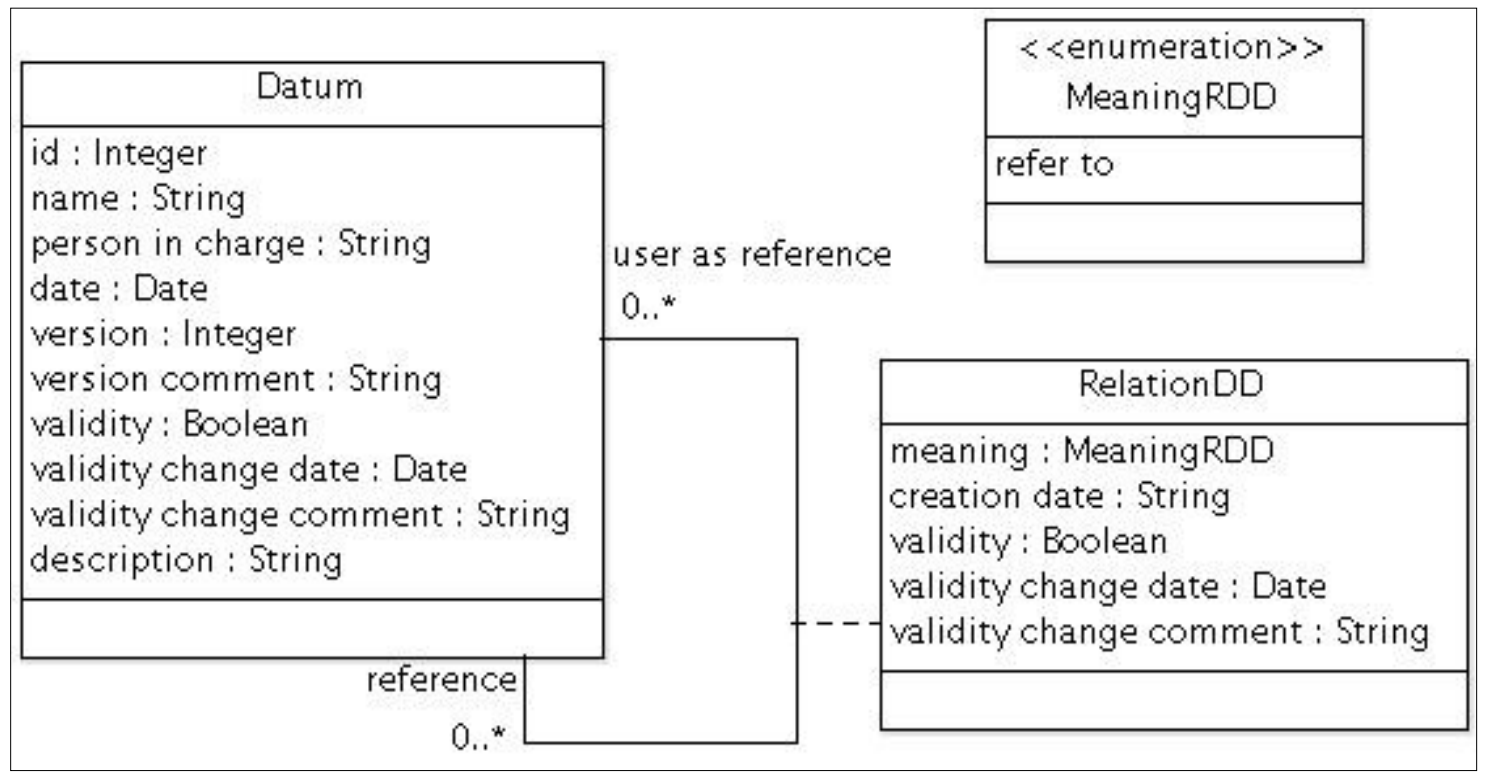


Figure 5: Datum CEKQ model.

The Activity class (Figure 6) also encapsulates the name of the activity, the person in charge of it and its id. The type of activity is used to specify whether the activity is manual, assisted or fully automated (depending on the expert application used). If the activity is assisted or fully automated, the application specifies the name of the corresponding expert application. Time indicators - maximum duration, minimum duration and average duration - enable activities to be analysed in terms of duration when optimisation is sought. The resource indicator, capacity flexibility, enables an evaluation to be made as to whether the activity can be optimised by increasing the number of resources. The operator represents the role of the person carrying out the activity.

\begin{tabular}{|c|c|}
\hline Activity & \\
\hline \multirow{3}{*}{$\begin{array}{l}\text { id : Integer } \\
\text { name: String } \\
\text { activity type : Activity type } \\
\text { application : String } \\
\text { maximum duration : Long } \\
\text { average duration : Long } \\
\text { duration : Long } \\
\text { capacity flexibility : Boolean } \\
\text { operator : String } \\
\text { person in charge : String } \\
\text { creation date : Date } \\
\text { version : Integer } \\
\text { version comment : String } \\
\text { validity : Boolean } \\
\text { validity change date : Date } \\
\text { validity change comment : String }\end{array}$} & $\begin{array}{c}<\text { <enumeration }>> \\
\text { Activity type }\end{array}$ \\
\hline & $\begin{array}{l}\text { manual } \\
\text { assisted } \\
\text { automated }\end{array}$ \\
\hline & \\
\hline
\end{tabular}

Figure 6: Activity CEKQ model.

A Process (Figure 7) has many properties similar to those of activities (id, name, person in charge, type of process, applications, duration and resource indicators, operators) to which an objective is added representing its purpose. The GraphicalRepresentation class enables an image to be encapsulated, expressing a process or part of this process in graphic format. This representation is identified by an id and integrated according to an order should it represent part of a process. The RelationPGraphicalR class enables a process to be linked to its sequenced graphic representations. The RelationPP1 and RelationPP2 classes enable the processes to be interlinked according to two types of relations. The first enables a hierarchical relationship to be represented, broken down into processes and sub-processes. The second enables representation of the fact that a process can reuse a process in order to avoid redundant descriptions. In particular, this is the case when in a Process 2 the same Sub-Process 1.1 already occurred in Process 1 and has already been described. 


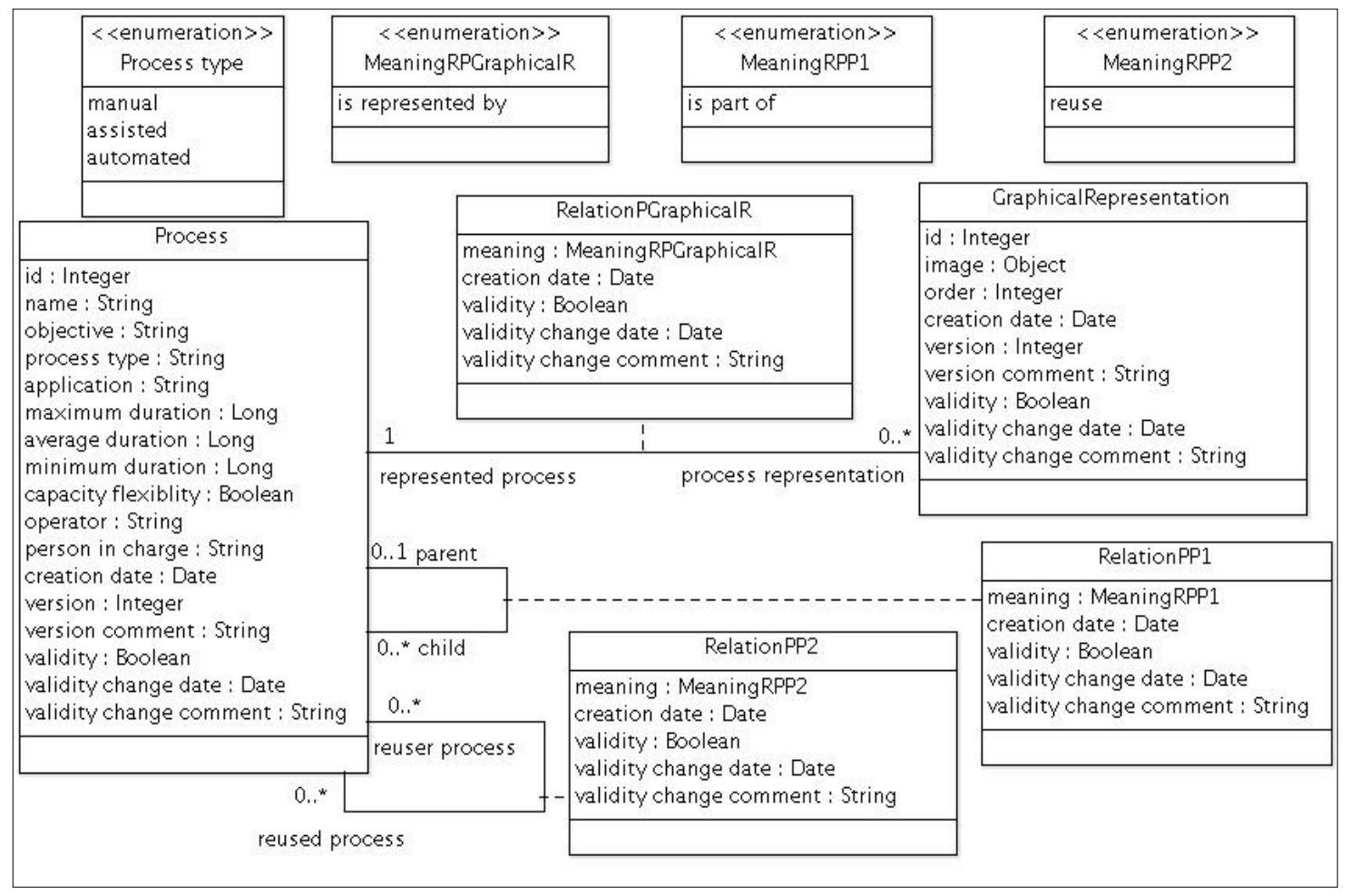

Figure 7: Process CEKQ model.

Generally speaking, the evolutionary component associated with integration of the encoded knowledge life-cycle is taken into account for a twofold purpose: to enable reconstruction of the evolution of the concepts proposed and those of the links they maintain with other concepts. The properties established to trace the evolution of the selected concepts are the concept version, the creation date of this version, a version comment justifying version transition, the validity of the concept version, the modification date of this validity and a comment on the modification of this validity. Previous versions of a concept are necessarily invalid since a new version replaces the previous one. However, this characteristic enables the obsolescence of the last version of a concept to be expressed. The second point concerns inter-concept relations. Since these relations are mainly described by their meaning and can only have one meaning, only the creation date and three validity characteristics are pertinent.

The Structuring core model is presented in Figure 8 (for reasons of simplification, the relations and properties already presented in Figures 5 to 7 do not appear).

The Focus class encapsulates the name of the network model concepts. The term Focus is used here in reference to Ranganathan's classification (Ranganathan, 1950). In this class, the name constitutes the concept identifier that cannot be used redundantly. The Facet class encapsulates the name of a facet and also refers to Ranganathan's classification. Relations can be set up between these classes. The association classes IndexingQcecDF, IndexingQcecAF and IndexingQcecPF represent the possibility of indexing a Datum, an Activity and a Process, respectively, on a particular Focus according to a unique meaning per Facet. The association class RelationFF represents the possibility of creating concept networks browsable via a unique hierarchical relation by Facet. The two possible types of relations are generalisation and composition. 


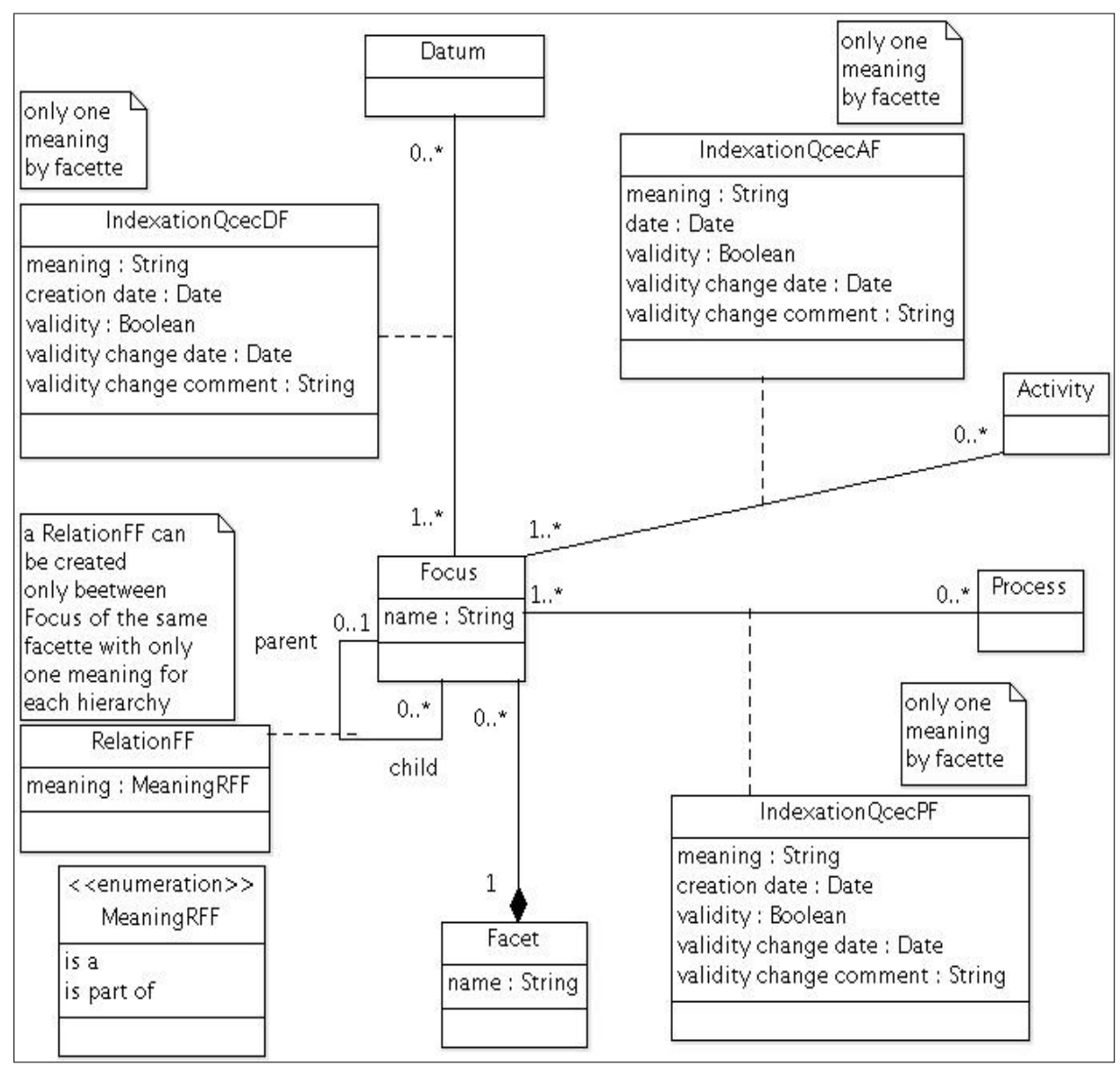

Figure 8: Structuring model.

The integration of the contextual aspect presupposes the explicit modelling of the existing link between knowledge support tools and metier redesign processes. Concerning the expert applications represented by the activity CEKQ, the link is modelled as presented in Figure 9. It introduces the RelationQcecAQcecP class with a composition meaning and integration of evolutionary aspects.

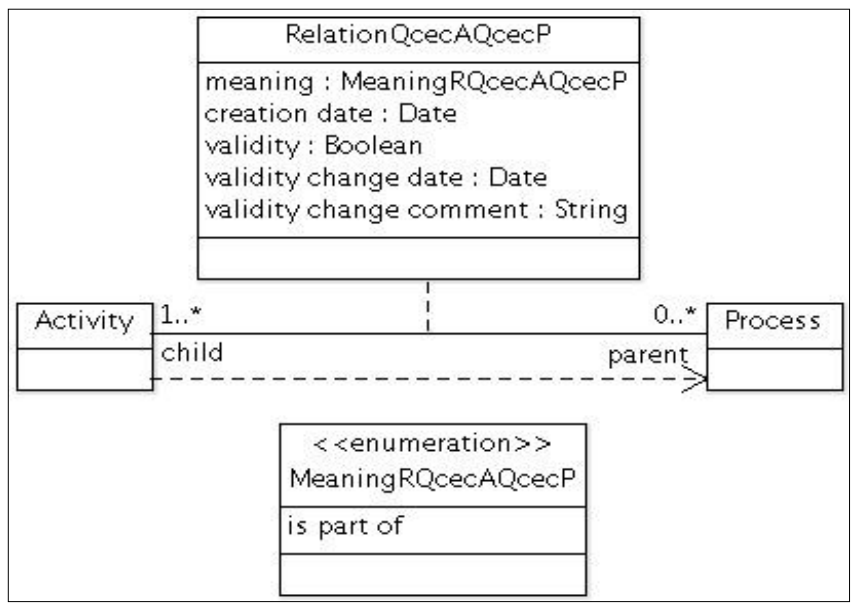

Figure 9: Activity CEQK - Process CEQK link.

Concerning the knowledge objects, the link with the business redesign processes is modelled (Figure 10) indirectly via a link between the Datum CEKQ and Activity CEKQ. This modelling is based on the IDEF0 method language, for which "The primary objectives of this standard are (notably) to provide a modelling technique that has the following characteristics (NIST, 1993): 
- Generic (for analysis of systems of varying purpose, scope and complexity);

- Rigorous and precise (for production of correct, usable models);

- Concise (to facilitate understanding, communication, consensus and validation);

- Conceptual (for representation of functional requirements rather than physical or organizational implementations);

- Flexible (to support several phases of the life cycle of a project)."

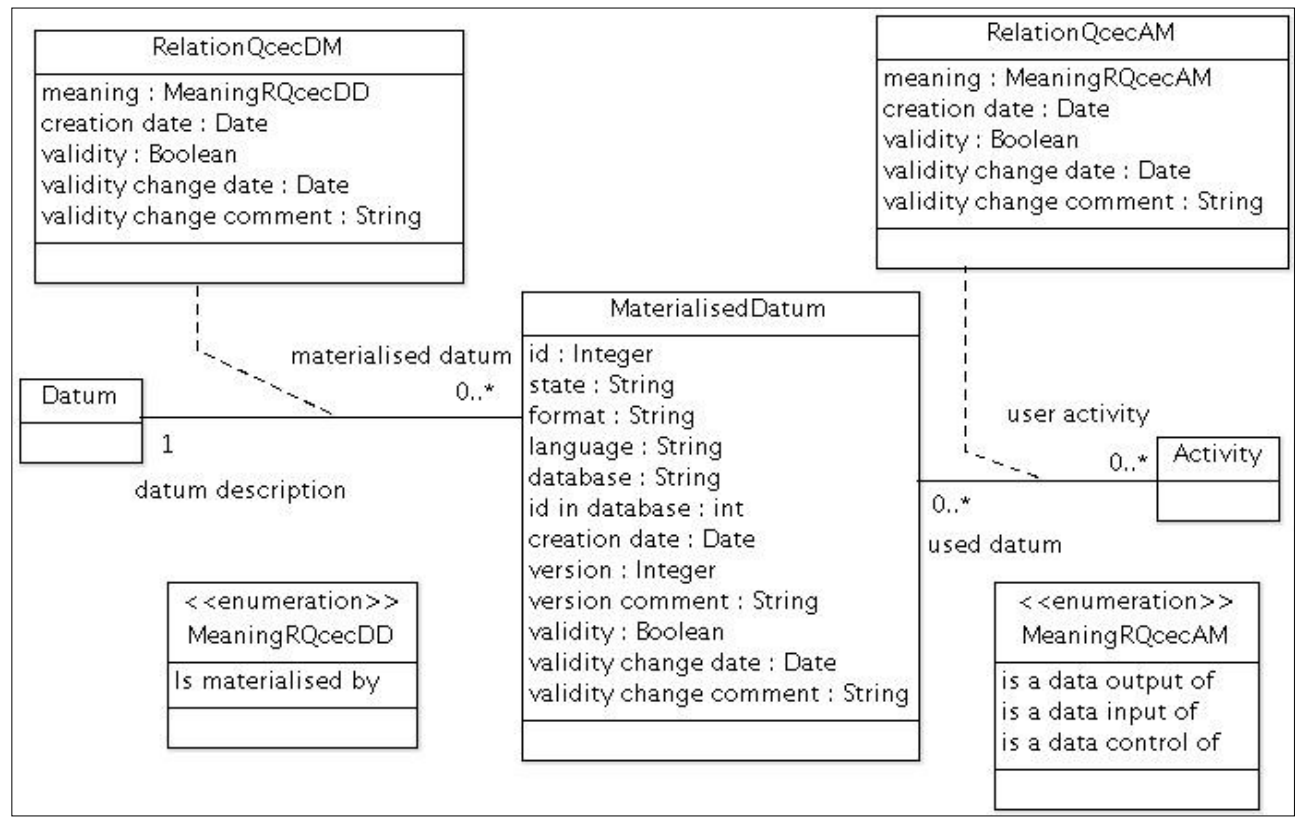

Figure 10: Datum CEKQ - Activity CEKQ link

We use the following notions again in this formalism:

- Function name, which will be represented by the name of an Activity relative to the Activity CEKQ (Figure 6),

- Input (data transformed by the function), Control (conditions required to produce correct data) and Output (data produced by the function), which will be respectively represented by a name of a Datum relative to a Datum CEKQs (Figure 5) and by the status of this Data.

A new class - MaterialisedDatum - has thus been defined. This class enables the various statuses that a MaterialisedDatum can take to be represented. In more concrete terms, this involves the statuses of reconfigurable types of knowledge objects (cf. Section 2.2). Static types only have one status. A Datum can then be linked to various MaterialisedData by means of a relation represented by the RelationQcecDM class. MaterialisedDatum also groups together a set of properties associated with the reified nature of a knowledge object and may change according to its status:

- the database property represents the identifier of the tool in which the knowledge object is managed (in view of the fact that several possible solutions exist - cf. Section 2.2).

- the id in database property which represents the identifier of the object under consideration in this tool.

- the format of the knowledge object (e.g. pdf, excel),

- the language in which the knowledge object was drafted (e.g. English, French).

The RelationQcecAM class enables the three types of relations recommended to be defined in the IDEFO method. Evolutionary aspects are also taken into account. 


\section{Validation of PKMS}

\subsection{Implementation}

A demonstrator, named PKMS (Process-oriented Knowledge Management System), implementing the model presented in Section 3 has been set up to validate its implementable nature and assess its instantiation on a practical level with our industrial partner for this work.

The technological choice made for the implementation of our conceptual model is that of a relational database in ".MDB" format, based on Microsoft Office Access 2003 software. This choice is due to the fact that the software has the sufficient characteristics to show the implementation feasibility and was easily accessible at the Renault Powertrain Technology Department. Since the UML language was derived from object-oriented programming methods, a model transcription stage was implemented using the rules defined in (Nanci and Espinasse, 1996) relying on the MERISE method (Quang, 1986). In view of the technological choice made, certain elements of the conceptual model have not been transcribed:

- the behaviour of the composition relation aimed at easy, consistent elimination of a facet,

- the constraints covering the uniqueness of relations with facets. It is hard to define these constraints in an easy and easily maintainable way in an Access database in ".MDB" format.

In addition to these elements that have not been transcribed, a default value type of constraints has been implemented using a specific table following the meta-modelling principle proposed in (Nanci and Espinasse, 1996).

Instantiation of the model and the query interface presupposes two means for using the demonstrator of PKMS. The first corresponds to the knowledge elicitation phase within which a knowledge support tool will be described by the person in charge. The second concerns the model viewing phase during which any member of the organisation can endeavour to access the description previously produced.

The elicitation phase is performed directly from the original Access 2003 software interface. The data is therefore specified by successive completion of tables. Specification consists of developing the faceted classification and of completing and then indexing the characteristics of knowledge support tools in relation to the data, activity and process cores.

The conceptual model viewing phase is obtained by means of four interfaces, representative of the 4-core architecture. An example is partially detailed in figures 11 and 12, which present two of these four interfaces. A designer in the Powertrain department is searching for a knowledge object of type SADC to realise a particular design task. He/she is so asking to the structuring core such request (Figure 11) and the PKMS tool gives the reference to the "SADC File Screw Assembly". By doubleclicking on it, the designer arrives at the Data core, with all the metadata for the knowledge object defined. In order to have a more precise understanding of the usage of such knowledge object, he/she can switch to the activities core (Figure 12), in which he/she can navigate through the different usages and in particular the activity "Copy nominal data of CAD model in SADC file". For such activity, he/she has access to, for example:

- the top left rectangular of the interface to the complete metadata of the activity (type, operator in charge, etc.),

- the top right rectangular of the interface, the complete referential of the activity and the process the activity is part of,

- the bottom rectangular, an IDEF0 illustration of the activity and its relations with specific knowledge objects. 


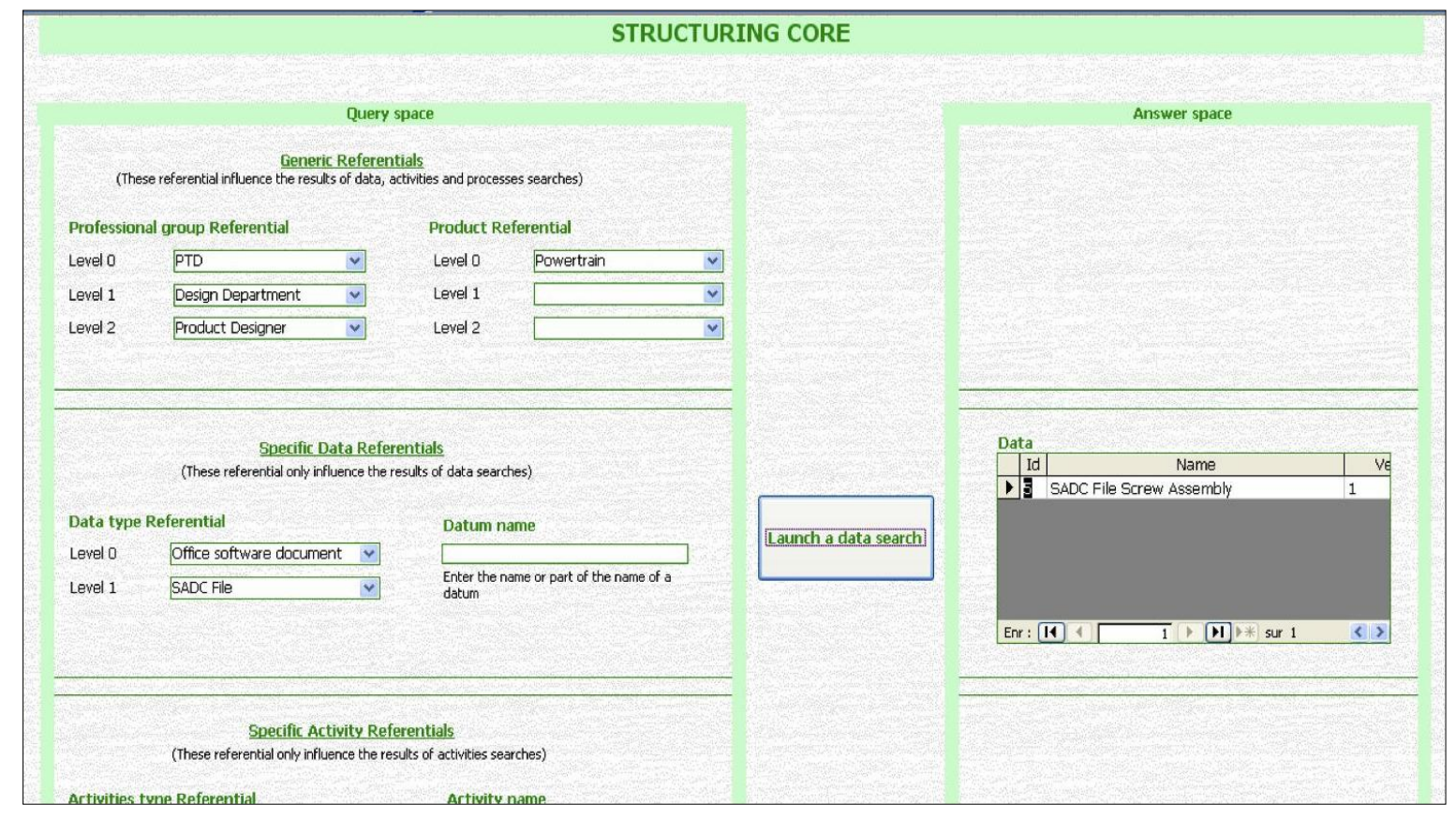

Figure 11: Extract from the Structuring core interface.

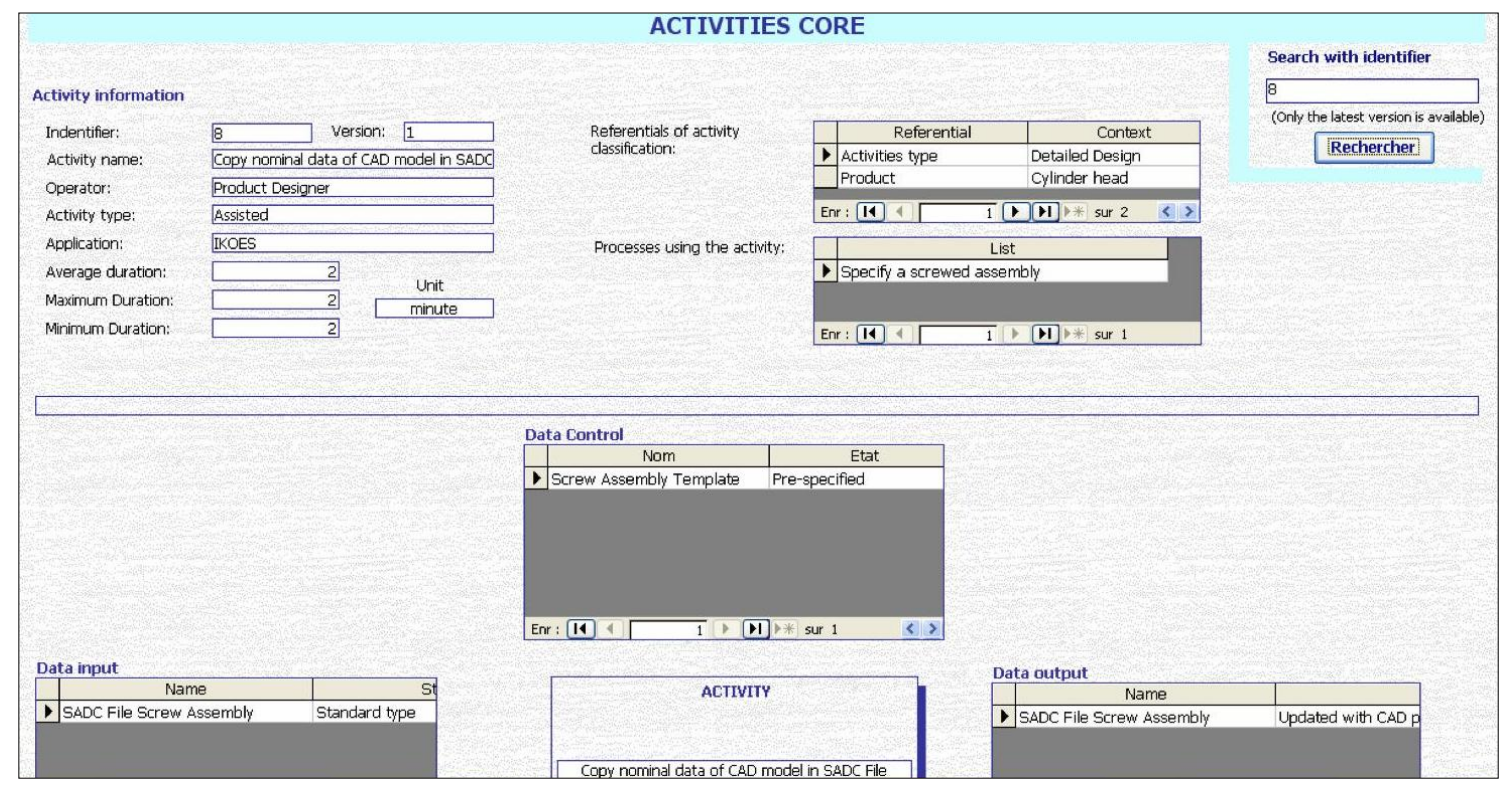

Figure 12: Extract from the Activity core interface.

\subsection{Discussion}

The demonstrator produced was presented to the Renault Knowledge Capitalisation Department. It received positive feedbacks, in particular concerning integration of the process aspect, and is expected to lead to optimisation of the system that is currently in operation. The question of the profitability of this optimisation is still nonetheless a core point of discussion by manufacturers. Although research work has already shown the positive impact on innovation and design lead times a posteriori when investment is made in knowledge management tools (Vaccaro et al., 2010), the impact aspect a priori would apparently merit investigation.

Moreover, the conceptual model was tackled from a cognitive science standpoint (on which the MASK framework is based). This choice of standpoint should enable individuals confronted with 
instantiation of this model to become conversant with it with little effort since the knowledge structuring proposed is generally close to the way in which this knowledge is actually stored in human memory. This viewpoint supposes that individuals possess a unique and therefore shared interpretative framework model for formatting their knowledge. This assumption is widely discussed within constructivist approaches whereby interpretative framework models might be personal to each individual and dependent upon the environment with which they are confronted. This consideration thus opens up the way to an increased number of possibilities for a conceptual framework (Uys et al., 2008) compared with the one presented in this article or to their absence by using generic research approaches based on the sole use of key words (of the folksonomy type or plain text search) since concept networks are apparently the result of personal construction. Between these two Manichean approaches, (Grundstein, 2012) have positioned the notion of commensurability, which states that although people have different interpretative schemas, there is an intersecting zone of varying size depending on the culture, which enables them to understand one another and on which the exchange of knowledge is based. The model proposed is therefore based on cognitive science, the work of which concerns this intersecting zone and is limited to manufacturing companies with a process-driven management approach due to the company culture in which the model was developed. Nonetheless, it is still difficult to accurately define its generic nature and it would be worth undertaking work on the characterisation of commensurability zones between individuals.

With regards to the contextual aspect addressed in Section 3 under the standpoint of process, the graphical language that is to be used has to be defined. It is clear that its formalisation according to systematically ad hoc language will also call for systematic ad hoc interpretation by the individuals confronted with this description. This situation will not facilitate an extension of the model sought via the analysis work proposed in Section 3. A sufficiently complete and common formalism must be proposed that enables the process to be described. On one hand it has to take the control of flows between activities into account because, during subsequent analysis of processes, the sequencing information is necessary to enable a critical path to be determined that may guide improvement choices. On the other hand, it has to allow the role of individuals or information systems to be specified. The interest of this constraint is to quickly identify, in processes description, where multiple stakeholders and/or information systems are involved and how the contribution of knowledge is distributed. An analysis of various business process (WFMC, 2008) languages should enable the selection of such a graphical language.

Finally, technology that is particularly accessible was selected for the development of the demonstrator, both for modelling the data (Access table), querying the data models (combined Access VBA / Access SQL algorithm) and the management of dynamic aspects (Access VBA). Although it enabled us to show that our proposals can materialise, the use of more robust, up-to-date technology should enable efficient deployment of the underlying information systems for these demonstrators. We believe that web technology is more appropriate for providing widespread access to encoded knowledge. It is possible to use it in order to define the accesses leading to various document formats. Moreover, by modifying the format of these documents (HTML5 ${ }^{1}$ being the format recommended by W3C), they will enable users to work in a standardised syntaxical environment, thus minimising the constraints when they wish to access the data contained in these documents. More specifically, use of the OWL language $(\mathrm{W} 3 \mathrm{C}, 2012)$ that will enable the logic properties of relations to be modelled (transitivity, reflexivity and symmetry etc.) opens up greater possibilities for querying models. It will nonetheless be necessary to familiarise developers with this data description language and the related query language (the W3C recommends SPARQL (W3C, 2008)), and also have inference engines to interpret the logic elements added. The cost of these technological changes will of course constitute a veritable obstacle to their deployment in industry. It will be necessary to justify this reasoning-oriented programming approach with considerable rigour for a number of pertinent application cases ((Liu and

1 http://www.w3.org/TR/html51/ 
Lim, 2010) propose a list of cases ranging from knowledge management systems to the interoperability of information systems).

\section{Conclusion and perspectives}

In manufacturing companies, products mainly stem from redesign processes, the speed of implementation and cost, which depend on the knowledge generated in previous design processes and the assimilation of this knowledge by current stakeholders.

In this article, the conceptual model for a Process-oriented Knowledge Management System (PKMS) has been proposed. The aim of this system is to foster the encounter between product redesign process stakeholders and the knowledge support tools made available to them to perform their activities. Since the instantiated model was the result of knowledge codification work, the codification formalism was analysed in order to foster its extension to the organisation. A demonstrator was produced to validate its implementable nature and the model was then instantiated using information available from our industrial partner, the Renault Powertrain Technology Department.

Proposals have been made regarding the orientation of future work, both from a conceptual and an economic and technological standpoint.

\section{Acknowledgment}

This work is part of a Ph.D. thesis project jointly undertaken with our industrial partner Renault (Powertrain Technology Design Department). 


\section{References}

(Ahmed and Wallace, 2001) Ahmed S., Wallace K.M., Identifying and supporting the knowledge needs of novice designers within the aerospace industry, Journal of Engineering Design, Vol. 15(5), pp. 475492, 2004.

(Alavi and Leidner, 2001) Alavi M.D., Leidner D., Knowledge management and knowledge management systems: conceptual foundations and research issues, MIS Quarterly, Vol. 25(1), pp. 106-127, 2001.

(Anantatmula, 2010) Anantatmula V.S., Impact of cultural differences on knowledge management in global projects, Journal of Information and Knowledge Management Systems, Vol. 40(3/4), pp. 239253, 2010.

(Baumard, 1999) Baumard P., Tacit knowledge in organizations. Sage publication Ltd., 1999.

(Baizet, 2004) Baizet Y., La gestion des connaissances en conception, Application à la simulation numérique chez Renault-DIEC. PhD thesis of University Joseph Fourier - Grenoble, 2004.

(Beylier et al., 2009) Beylier C., Pourroy F., Villeneuve F., Mille A., A collaboration-centred approach to manage engineering knowledge: a case study of an engineering SME, Journal of Engineering Design, Vol. 20(6), pp. 523-542, 2009.

(Ben-Ari and Yeshno, 2006) Ben-Ari M., Yeshno T., Conceptual models of software artifacts, Interacting with Computers, Vol. 18(6), pp. 1336-1350, 2006.

(Bernard and Tichkiewitch, 2008) Bernard A., Tichkiewitch S., Methods and tools for effective knowledge life-cycle management, Springer, 2008.

(Bluntzer et al., 2009) Bluntzer J.B., Sagot J.C., Mahdjoud M., Knowledge Based Engineering approach through CAD systems: results of two years of experimentation in an industrial design office, Proceedings of CIRPDesign conference, Cranfield (UK), 2009.

(Cacciatori, 2008) Cacciatori E., Memory objects in project environments: Storing, retrieving and adapting learning in projects-based firms, Research Policy, Vol. 37(9), pp. 1591-1601, 2008.

(Chandrasegaran et al., 2013) Chandrasegaran S.K., Ramani K., Sriram R.D., Horváth I., Bernard A., Harik R.F., Gao W., The evolution, challenges, and future of knowledge representation in product design systems, Computer-Aided Design, Vol. 45, pp. 204-228, 2013.

(Chen and Huang, 2012) Chen Y.Y., Huang H.L., Knowledge management fit and its implications for business performance: A profile deviation analysis, Knowledge-Based Systems, Vol. 27, pp. 262-270, 2012.

(D'Adderio, 2003) D'Adderio L., Configuring software, reconfiguring memories: the influence of integrated systems on the reproduction of knowledge and routines, Industrial and Corporate Change, Vol. 12(2), pp. 321-350, 2003.

(Ermine, 2005) Ermine J.L., A theoretical and formal model for Knowledge Management Systems, Proceedings of ICICKM'2005 (International Conference on Intellectual Capital and Knowledge Management), Dubai, pp. 187-199, 2005. 
(Fortineau et al., 2014) Fortineau V., Fiorentini X., Paviot T., Louis-Sidney L., Lamouri S., Expressing formal rules within ontology-based models using SWRL: an application to the nuclear industry. International Journal of Product Lifecycle Management, Vol. 7(1), pp. 75-93, 2014.

(Gero, 1990) Gero J.S., Design Prototypes: A knowledge representation schema for design, Al Magazine, Vol. 11(4), pp. 26-36, 1990.

(Grundstein, 2012) Grundstein M., Three postulates that change knowledge management paradigm. New research on knowledge management models and methods. Chapter 1. Edition Huei-Tse Hou, 2012.

(Hanisch et al., 2009) Hanisch B., Lindner F., Mueller A., Wald A., Knowledge management in project environments, Journal of Knowledge Management, Vol. 13(4), pp. 148-160, 2009.

(Henderson, 1991) Henderson K., Flexible sketches and inflexible data bases: visual communication, conscription devices, and boundary objects in design engineering. Science Technology Human Values, Vol. 16(4), pp. 448-473, 1991.

(ISO 9000, 2005) ISO 9000. Quality management systems - Fundamentals and vocabulary, 2005

(Karacapilidis, 2002) Karacapilidis N., Modeling discourse in collaborative work support systems: A knowledge representation and configuration perspective, Knowledge-Based Systems, Vol. 15(7), pp. 413-422, 2002.

(Kingston, 1998) Kingston J.K.C., Designing knowledge based systems: the CommonKADS design model, Knowledge-Based Systems, Vol. 11(5-6), pp. 311-319, 1998.

(Kop and Hill, 2008) Kop R., Hill A., Connectivism: Learning theory of the future or vestige of the past, The International Review of Research in Open and Distance Learning, Vol. 9(3), 2008.

(Johansson et al., 2013) Johansson T., Moehler R.C., Vahidi R., Knowledge Sharing Strategies for Project Knowledge Management in the Automotive Sector, Procedia - Social and Behavioral Sciences, Vol. 74, pp. 295-304, 2013.

(Liao, 2003) Liao S.H., Knowledge management technologies and applications-literature review from 1995 to 2002, Expert Systems with Applications, Vol. 25(2), pp. 155-164, 2003.

(Liu and Lim, 2010) Liu Y., Lim S.C.J. Using ontology for design information and knowledge management: a critical review. Proceedings of CIRPDesign Conference, Nantes, France, 2010.

(Louis-sidney et al, 2011) Louis-Sidney L., Cheutet V., Lamouri S., Puron O., Mezza A., A conceptual model for the implementation of an Inter-Knowledge Objects Exchange System (IKOES) in automotive industry, Engineering Applications of Artificial Intelligence, Vol. 25(5), pp. 1090-1101, 2012.

(McMahon et al., 2004) McMahon C., Lowe A., Culley S., Knowledge management in engineering design: personalization and codification, Journal of Engineering Design, Vol. 15(4), pp. 307-325, 2004.

(Miller and Mukerji, 2003) Miller J., Mukerji J., MDA Guide version 1.0.1. http://www.omg.org/cgibin/doc?omg/03-06-01 (link validated in December 2012), 2003.

(MOKA, 2000) MOKA, MOKA: Objectives. http://web1.eng.coventry.ac.uk/moka/mokaobjectives.htm (link validated in December 2012), 2000.

(Nanci and Espinasse, 1996) Nanci D., Espinasse B., Ingénierie des systèmes d'information, Merise, Deuxième génération. Edition Sybex (Troisième édition), 1996. 
(Ng et al., 2012) Ng A.H.H., Yip M.W., Din S.B., Bakar N.A., Integrated Knowledge Management Strategy: A Preliminary Literature Review, Procedia - Social and Behavioral Sciences, Vol.57, pp. 209214, 2012.

(Ngai and Chan, 2005) Ngai E.W.T., Chan E.W.C., Evaluation of knowledge management tools using AHP, Expert Systems with Applications, Vol. 29(4), pp. 889-899, 2005.

(NIST,1993) National Institute of Standards and Technology (NIST), Integration DEfinition for Function modeling (IDEF0), 1993.

(Owen and Horváth, 2002) Owen R, Horvath I., Towards product-related knowledge asset warehousing in enterprises, Proceedings of the $4^{\text {th }}$ international TMCE symposium, 2002.

(Pahl et al., 2007) Pahl G., Beitz W., Feldhusen J., Grote K.H., Engineering Design-A Systematic Approach, Springer ( $3^{\text {rd }}$ Edition), Berlin, 2007.

(Quang, 1986) Quang P.T., MERISE - a french methodology for information-systems analysis and design, Journal of systems management, Vol. 37(3), pp. 21-24, 1986.

(Ranganathan, 1950) Ranganathan S.R., Classification, coding and machinery for search, http://unesdoc.unesco.org/images/0013/001333/133325eo.pdf (link validated in December 2012), 1950.

(Ruggles, 1997) Ruggles R., Knowledge management tools, Oxford: Butterworth-Heinemann, 1997.

(Stokes, 2001) Stokes M., Managing Engineering Knowledge; MOKA: Methodology for Knowledge Based Engineering Applications. Professional Engineering Publishing, London, 2001.

(Szykman et al., 2001) Szykman S, Sriram R, Regli W., The role of knowledge in next-generation product development systems, Journal of Computing and Information Science in Engineering, Vol. 1(1), pp. 3-11, 2001.

(Tiwana and Ramesh, 2001) Tiwana A, Ramesh B., A design knowledge management system to support collaborative information product evolution, Decision Support Systems, Vol. 31(2), pp.241-62, 2001.

(Triantaphyllou et al., 2002) Triantaphyllou E, Liao T.W, lyengar S.S., A focused issue on data mining and knowledge discovery in industrial engineering, Computers and Industrial Engineering, Vol. 43(4), pp. 657-659, 2002.

(Tsuchiya, 1993) Tsuchiya S., Improving Knowledge Creation Ability through Organizational Learning, Proceedings of International Symposium on the Management of Industrial and Corporate Knowledge (ISMICK), Compiègne-France, 1993.

(Uys et al., 2008) Uys W., Uys E., Lutters E., Du Preez N., Improved utilisation of organisational documents using a conceptual framework, in Bernard A., Tichkiewitch S., Methods and tools for effective knowledge life-cycle management, Springer, pp. 347-361, 2008.

(Vaccaro et al., 2010) Vaccaro A., Parente R., Veloso F.M., Knowledge Management Tools, InterOrganizational Relationships, Innovation and Firm Performance, Technological Forecasting and Social Change, Vol. 77(7), pp. 1076-1089, 2010.

(Verhagen et al., 2012) Verhagen W.J.C., Bermell-Garcia P., Van Dijk R.E.C., Curran R., A critical review of Knowledge-Based Engineering: An identification of research challenges, Advanced Engineering Informatics, Vol. 26, pp. 5-15, 2012. 
(Vroom and Olieman, 2011) Vroom R.W., Olieman A.M., Sharing relevant knowledge within product development. International Journal of Product Development, Vol. 14(1), pp. 34-52, 2011.

(W3C, 2012) World Wide Web Consortium (W3C), OWL 2 Web Ontology Language Document Overview (Second Edition), http://www.w3.org/TR/owl2-overview/ (link validated in December 2012), 2012.

(Watson, 1999) Watson I., Cased-based reasoning is a methodology not a technology, KnowledgeBased Systems, Vol. 12(5-6), pp. 303-308, 1999.

(WFMC, 2008) Workflow Management Coalition, Terminology and Glossary English, http://www.wfmc.org/Glossaries-FAQs/View-category.html (link validated in December 2012), 2008.

(Zacklad and Grundstein, 2001) Zacklad M., Grundstein M., Ingénierie et capitalisation des connaissances, Edition Hermès Sciences publication, pp. 15-22, 2001.

(Zins, 2007) Zins, C., Conceptual Approach for Defining Data, Information, and Knowledge, Journal of the American Society for Information Science and Technology, Vol. 58(4), pp. 479-493, 2007. 